\section{AB1382-HPR COMPARISON OF EFFICACY OF DIFFERENT REHABILITATION APPROACHES IN INDIVIDUALS WITH KNEE OSTEOARTHRITIS}

Elif Baysal ${ }^{1}$, Miray Budak ${ }^{2}$, Esra Atılgan ${ }^{3}$, Devrim Tarakcl ${ }^{4} .{ }^{1} /$ stanbul Medipol University, Istanbul, Turkey; ${ }^{2}$ Istanbul Medipol University, Ergotherapy, Istanbul, Turkey, ${ }^{3}$ Istanbul Medipol University, Physical Therapy and Rehabilitation, Istanbul, Turkey, ${ }^{4}$ Istanbul Medipol University, Ergotherapy, Istanbul, Turkey

Background: Osteoarthritis $(\mathrm{OA})$ is the most common rheumatologic disease in the world, resulting primarily in progressive cartilage destruction OA-induced changes are the main cause of disability and are mostly seen in the knee joint.

Objectives: To investigate the effects of different rehabilitation practices on the range of motion, muscle strength, pain, physical function and quality of life in patients with knee OA.

Methods: Thirty patients between the ages of 40-65 with knee OA were included in the study and divided into 3 groups. Transcutaneous Electrical Nerve Stimulation (TENS), ultrasound, hotpack/coldpack and home exercise program were given to the 1 . group $(n=10)$ for 15 days. 2. group $(n=10)$ received three doses of Platelet-Rich Plasma (PRP) followed by home exercise program for 15 days. The control group $(n=10)$ received only home exercise program for 15 days. All individuals were evaluated using 'Goniometer' for Range of Motion (ROM), 'Manual Muscle Test' for M. Quadriceps femoris muscle strength, 'Visual Analogue Scale' for pain, 'The Western Ontario and McMaster Universities Arthritis (WOMAC) Scale' for physical function and 'Short Form-12 Quality of Life Scale Mental (SF-12 - MC) and Physical Component (SF-12 - PC)' for quality of life at baseline and end of treatment.

Abstract AB1382HPR Table 1. Results before and after treatment

\begin{tabular}{|c|c|c|c|c|c|c|c|c|c|c|}
\hline & \multicolumn{3}{|c|}{ 1. Group } & \multicolumn{3}{|c|}{ 2. Groug } & \multicolumn{3}{|c|}{ Control Group } \\
\hline & & \multirow{2}{*}{$\begin{array}{c}\begin{array}{c}\text { Pxe } \\
\text { Ireeatuent }\end{array} \\
\text { AvgsSD }\end{array}$} & \multirow{2}{*}{$\begin{array}{c}\begin{array}{c}\text { Post } \\
\text { Treatment }\end{array} \\
\text { AxstSD }\end{array}$} & \multirow[t]{2}{*}{$\mathbb{R}^{*}$} & \multirow{2}{*}{$\begin{array}{c}\begin{array}{c}\text { Pre } \\
\text { Treatoment }\end{array} \\
\text { AxatSD }\end{array}$} & \multirow{2}{*}{$\begin{array}{c}\begin{array}{c}\text { Post } \\
\text { Treatcoent }\end{array} \\
\text { AvgsSDR }\end{array}$} & \multirow[t]{2}{*}{$R^{*}$} & $\begin{array}{c}\text { Pret } \\
\text { Ireatpent }\end{array}$ & \multirow{2}{*}{ 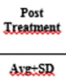 } & \multirow[t]{2}{*}{$\mathrm{R}^{*}$} \\
\hline & & & & & & & & Arz:SD & & \\
\hline \multirow{2}{*}{ 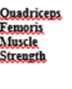 } & Right & $4,50 \pm 0,52$ & $4,55 \pm 0,49$ & 0,317 & $4,30 \pm 0,53$ & $4,45 \pm 0,53$ & 0,083 & $4,45 \pm 0,36$ & $4,60 \pm 0,45$ & 0,083 \\
\hline & Leff & $4,35 \pm 0,62$ & $4,40 \pm 0,61$ & 0,317 & $4,35 \pm 0,52$ & $4,45 \pm 0,55$ & 0,157 & $4,50 \pm 0,52$ & $4,60 \pm 0,39$ & 0,157 \\
\hline \multirow[t]{2}{*}{ Knee ROM } & Right & $91,3 \pm 28,5$ & $98,0 \pm 26,4$ & 0,042 & $99,0 \pm 10,7$ & $101 \pm 9,06$ & 0,046 & $111 \pm 0,73$ & $113 \pm 8,23$ & 0,083 \\
\hline & Left & $94,0 \pm 24,0$ & $105 \pm 10,9$ & 0,026 & $94,0 \pm 13,2$ & $97,5 \pm 13,5$ & 0,035 & $106 \pm 14,3$ & $109 \div 13,6$ & 0,063 \\
\hline \multirow[t]{2}{*}{ vas } & Retivg & $3,00 \pm 2,53$ & $1,40 \pm 2,06$ & 0,067 & $1,50 \pm 3,17$ & $0,80 \pm 1,75$ & 0,180 & $1,00 \pm 1,05$ & $0,40 \pm 0,69$ & 0,034 \\
\hline & Activity & $6,50 \pm 3,27$ & $2,00 \pm 2,35$ & 0,007 & $4,90 \pm 3,34$ & $2,30 \pm 2,62$ & 0,007 & $2,80 \pm 2,14$ & $1,00 \pm 1,33$ & 0,011 \\
\hline \multicolumn{2}{|c|}{ WOMAC } & $56,3 \pm 12,2$ & $37,8 \pm 16,5$ & 0,007 & $45,9 \pm 21,2$ & $39,1+20,0$ & 0,005 & $35,2 \pm 12,1$ & $28,1 \pm 13,5$ & 0,009 \\
\hline \multirow[t]{2}{*}{$S F-12$} & PC & $33,4 \pm 10,6$ & $37,0 \pm 10,8$ & 0,139 & $40,8 \pm 5,99$ & $40,946,99$ & 0,333 & $41,2 \pm 9,48$ & $47,1 \pm 10,1$ & 0,037 \\
\hline & MC & $48,5 \pm 10,4$ & $58,1 \pm 4,14$ & 0,022 & $37,1 \pm 11,4$ & $46,0 \pm 15,9$ & 0,028 & $48,6 \pm 12,5$ & $49,8 \pm 11,2$ & 0,799 \\
\hline
\end{tabular}

Abstract AB1382HPR Table 2. Comparison of pre- and post-treatment measurement results between groups

\begin{tabular}{|c|c|c|c|c|c|c|c|c|c|}
\hline & \multicolumn{4}{|c|}{ Bxe- Ireatment } & \multicolumn{3}{|c|}{ Post - Treatment } & \multirow{3}{*}{$\begin{array}{c}\text { Betricen Gropos } \\
\mathrm{R}^{*}\end{array}$} \\
\hline & & \multirow{2}{*}{\begin{tabular}{|l|}
$\begin{array}{c}\text { 1.Group } \\
\mathrm{m}=10\end{array}$ \\
dvestSR \\
\end{tabular}} & \multirow{2}{*}{\begin{tabular}{c|}
$\substack{\text { 2.Group } \\
n=10}$ \\
drstSD
\end{tabular}} & \multirow{2}{*}{\begin{tabular}{|c|c|}
$\begin{array}{c}\text { Control } \\
\text { Grapp } \\
z=10\end{array}$ \\
AxstSR \\
\end{tabular}} & \multirow[b]{2}{*}{$R^{*}$} & $\begin{array}{c}\text { 1.Group } \\
\mathrm{p}=10\end{array}$ & $\begin{array}{l}\text { 2.Group } \\
p=10\end{array}$ & $\begin{array}{l}\text { Coutrol } \\
\text { Growp } \\
B=10\end{array}$ & \\
\hline & & & & & & dugtSD & AvesSD & ArstSR & \\
\hline \multirow{2}{*}{$\begin{array}{l}\text { Quadricess } \\
\text { Eemoons } \\
\text { Sluscle } \\
\text { Strengeth }\end{array}$} & Right & $4,50 \pm 0,52$ & $4,30 \pm 0,53$ & $4,45 \pm 0,36$ & ,652 & $4,55 \pm 0,49$ & $4,45 \pm 0,55$ & $4,60 \pm 0,45$ & 0,487 \\
\hline & Let & $4,35 \pm 0,62$ & $4,35 \pm 0,52$ & $4,50 \pm 0,52$ &, 775 & $4,40 \pm 0,61$ & $4,45 \pm 0,55$ & $4,60 \pm 0,39$ & 0,793 \\
\hline \multirow[t]{2}{*}{ Kneer ROM } & Right & $91,5 \pm 28,5$ & $99,0 \pm 10,7$ & $111 \pm 9,73$ & ,038 & $98,0 \pm 26,4$ & $101 \pm 9,06$ & $113 \pm 8,23$ & 0,322 \\
\hline & Left & $94,0 \pm 24,0$ & $94,0 \pm 13,2$ & $105 \leqslant 14,3$ &, 119 & $105 \pm 10,9$ & $97,5 \pm 13,5$ & $109 \pm 13,6$ & 0,375 \\
\hline \multirow[t]{2}{*}{ vas } & Recting & $3,00 \pm 2,53$ & $1,50 \pm 3,17$ & $1,00 \pm 1,05$ & , 061 & $1,40 \pm 2,06$ & $0,80 \pm 1,75$ & $0,40 \pm 0,69$ & 0,175 \\
\hline & Activity & $6,50 \pm 3,27$ & $4,90 \pm 3,34$ & $2,80 \pm 2,14$ & ,037 & $2,00 \pm 2,35$ & $2,30 \pm 2,62$ & $1,00 \pm 1,33$ & 0,031 \\
\hline \multicolumn{2}{|l|}{ WOMAC } & & $40,8 \pm 5,99$ & $41,2 \pm 0,48$ & ,113 & $37,0 \pm 10,8$ & $40,9 \pm 6,99$ & $47,1 \pm 10,1$ & 0,013 \\
\hline \multirow[t]{2}{*}{ SF-12 } & PC & $56,3 \pm 12,2$ & $45,9 \pm 21,2$ & $35,2 \pm 12,1$ & 007 & $37,8 \pm 16,5$ & $39,1 \pm 20,0$ & $28,1 \pm 13,5$ & 0,173 \\
\hline & MC & $48,5 \pm 10,4$ & $37,1 \pm 11,4$ & $48,6 \pm 12,5$ & ,059 & $58,144,14$ & $46,0 \pm 15,9$ & $49,8 \pm 11,2$ & 0,107 \\
\hline
\end{tabular}

Results: Statistically significant difference was found at pain and WOMAC score at the time of activity in all groups (Table 1). Statistically significant difference was found at ROM and SF-12 MC score in group 1 and 2; at resting pain and SF-12 PC score in control group ( $p<0.05)$ (Table 2). Conclusion: In addition to electrotherapy treatment and PRP in knee OA treatment, it is thought that home exercise program can be used to relieve symptoms and improve quality of life in knee OA.

\section{REFERENCES}

[1] Huang GL, Hua S, Yang TM, et al. Platelet-rich plasma shows beneficial effects for patients with knee osteoarthritis by suppressing inflammatory factors. Exp Ther Med. 2018; doi: 10.3892/etm.2018.5794.

[2] Qiestad B, Juhl C, Eitzen I, et al. Knee extensor muscle weakness is a risk factor for development of knee osteoarthritis. A systematic review and meta-analysis. Osteoarthr Cartilage. 2015; 23:171-7.

[3] Reese NB, Bandy WD. Joint Range of Motion and Muscle Length Testing Philadelphia: Elsevier Health Sciences; 2016

[4] Huang L, Guo B, Xu F, et al. Effects of quadriceps functional exercise with isometric contraction in the treatment of knee osteoarthritis. Int $\mathrm{J}$ Rheum Dis. 2017; $21: 952-959$

[5] Huang PH, Wang CJ, Chou WY, et al. Short-term clinical results of intraarticular PRP injections for early osteoarthritis of the knee. Int J Surg. 2017; 42:117-122.

[6] Martini LI, Via AG, Fossati C, et al. Single platelet-rich plasma injection for early stage of osteoarthritis of the knee. Joints. 2017; 5:2-6.

[7] Angoorani $\mathrm{H}$, Mazaherinezhad A, Marjomaki O, et al. Treatment of knee osteoarthritis with platelet-rich plasma in comparison with transcutaneous electrical nerve stimulation plus exercise: a randomized clinical trial. Med $J$ Islam Repub Iran. 2015; 27; 29:223.

Disclosure of Interests: None declared DOI: 10.1136/annrheumdis-2019-eular.7960

\section{AB1383-HPR THE VALIDITY AND RELIABILITY OF UNSUPPORTED UPPER LIMB EXERCISE TEST IN INDIVIDUALS WITH RHEUMATOID ARTHRITIS}

S. Yaprak Cetin ${ }^{1}$, Bilge Basakci Calik ${ }^{2}$, Ayse Ayan ${ }^{3}$, Ugur Cavlak ${ }^{4} .{ }^{1}$ Akdeniz University, Deparment of Physiotherapy and Rehabilitation, Antalya, Turkey; ${ }^{2}$ Pamukkale University, School of Physiotherapy and Rehabilitation, Denizli, Turkey, ${ }^{3}$ Antalya Education and Research Hospital, Rheumatology, Antalya, Turkey, ${ }^{4}$ European University of Lefke, Physiotherapy and Rehabilitation, Antalya, Turkey

Background: Rheumatoid arthritis (RA) is a systemic, inflammatory disease that causes pain, joint destruction and disability. RA affects the function of the hand and upper extremities; function deteriorates as the disease progresses and affects independence. Unsupported upper-limb exercise (UULEX) test was developed to evaluate upper extremity function and endurance in individuals with Chronic Obstructive Pulmonery Disease. It is suggested that this test can be used in other clinical cases with arm disabilities.

Objectives: The aim of this study was to examine whether the UULEX Test is valid and reliable in individuals with RA

Methods: 71 individuals with RA (15 male, 56 female) with an average age of 52.1510 .11 were included in the study. The Intraclass Correlation Coefficient (ICC) was used to assess the reliability of the UULEX test Each individual was assessed by one physiotherapists in two different sessions, a week apart. The correlations of the UULEX test with Disabilities Arm, Shoulder and Hand (DASH), Health Assessment Questionnare (HAQ), 30 sec Push Up Test and 6 Peg Board Ring Test were assessed for concurrent validity.

Results: Intrarater reliability of final level, final weight, duration of the UULEX Test were determined to be excellent $(I C C=0.922,0.960,0.958)$. A moderate to excellent correlation was found between UULEX Test and DASH, HAQ, $30 \mathrm{sec}$ Push Up Test and 6 Peg Board Ring Test $(\mathrm{p}<0.05)$.

Conclusion: The results of this study showed that the UULEX test is a valid and reliable method in the assessment of upper extremity endurance in individuals with RA.

\section{REFERENCES}

[1] - Manning VL, Hurley MV, Scott DL, Coker B, Choy E. Bearne LM. Education, Self-Management, and Upper Extremity Exercise Training in People With Rheumatoid Arthritis: A Randomized Controlled Trial. Arthritis Care \& Research 2014; 66, 2: 217227.

[2] - Hammond A, Prior Y, Tyson S. Linguistic validation, validity and reliability of the British English versions of the Disabilities of the Arm, Shoulder and 